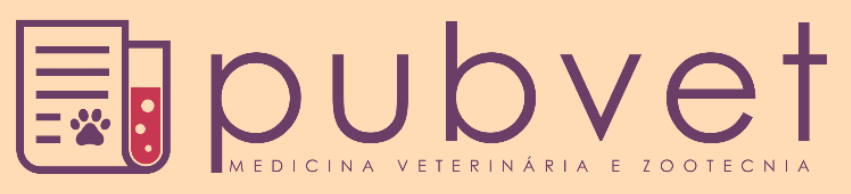

https://doi.org/10.31533/pubvet.v15n01 a726.1-8

\title{
Perfil da propriedade rural em diferentes bacias leiteiras e sua influência no desempenho zootécnico da atividade
}

\author{
Dayane Aparecida Santos ${ }^{*}{ }^{+\infty}$, Elisa Cristina Modesto ${ }^{20}$, Fernanda Giácomo Ragazzi ${ }^{10}$, \\ Thérèsse Camille Nascimento Holmström ${ }^{10}$, Nelma Pinheiro Fragata ${ }^{109}$
}

${ }^{I}$ Universidade Federal Rural do Rio de Janeiro, IZ-DPA - Seropédica, RJ.

${ }^{2}$ Universidade Federal do Rio Grande do Sul, DZ - Porto Alegre, RS.

*Autor para correspondência, E-mail: dayane.a.s@hotmail.com

\begin{abstract}
Resumo. Foi analisado um banco de dados relativos a produtores de leite fornecedores de uma indústria de transformação de leite e produção de lácteos de âmbito nacional de propriedades localizadas nas regiões Nordeste, Sul e Sudeste do Brasil. O horizonte de informações foi de 48 meses e cada técnico ou produtor preencheu um questionário, perfazendo um total de 85 amostras de produtores de leite de diferentes regiões do território nacional que, após eliminação de inconsistências e incongruências, permitiu a uma amostra consistente de 33 produtores. Foram feitas análises de desempenho zootécnico, utilizandose o procedimento ANOVAG do programa SAEG, versão 9.1 (UFV, 2007), sendo as médias comparadas por teste Tukey ao nível máximo de 5\% de erro. No Nordeste, os produtores possuíam maiores níveis de escolaridade e, em sua maioria, residem na propriedade leiteira, assim como os produtores das bacias Sudeste e Sul. A maioria dos funcionários das propriedades estudadas possuem baixo nível de escolaridade, residem na propriedade e são do gênero masculino. Dentro dos indicadores de desempenho zootécnico, a produtividade por área e por funcionário, a produção de leite por vaca por dia e por lactação foram superiores na bacia Sul.
\end{abstract}

Palavras-chave: Bacias leiteiras, perfil social, produção de leite

\section{Profile of the rural farms in different dairy belts and its influence on the animal performance of the activity}

\begin{abstract}
A database was analyzed related to milk producers who are linked to dairy processing industries located in the Northeast, South, and Southeast regions of Brazil. The economic space lasted 48 months, each technician or producer filled a questionnaire, completing a total of 85 milk producers from different regions of the national territory. After eliminating inconsistencies and discrepancies, the database allowed a consistent sample of 33 producers. Data on animal performance was subjected to ANOVAG from the SAEG program, version 9.1 (UFV, 2007), and averages were evaluated by the Tukey test at the level of 5\% of error probability. Farmers from the Northeast had higher levels of education, and the majority of these ones were living in the dairy property, as well as the milk producers from the Southeast and South of Brazil. Most of the employees of the analyzed properties were males and had a lower level of education; they were living in the properties where they worked. Within the animal performance index, the productivity by area and by the employee, the daily milk production by the cow, and by lactation were highest in the South milk producers.
\end{abstract}

Keywords: Dairy belts, social profile, milk production 


\section{Perfil de la propiedad rural en diferentes cuencas lecheras y su influencia en el desempeño zootécnico de la actividad}

Resumen. Se analizó una base de datos de los productores de leche que son proveedores de una industria nacional de procesamiento y productos lácteos con propiedades ubicadas en las regiones noreste, sur y sudeste de Brasil. El horizonte de información fue de 48 meses y cada técnico o productor completó un cuestionario, completando un total de 85 muestras de productores de leche de diferentes regiones del país, lo que, después de eliminar inconsistencias e incongruencias, permitió una muestra consistente de 33 productores. Los análisis del rendimiento zootécnico se realizaron utilizando el procedimiento ANOVAG del programa SAEG, versión 9.1 (UFV, 2007), con los promedios comparados por la prueba de Tukey en el nivel máximo de error del 5\%. En el noreste, los productores tenían mayores niveles de enseñanza y, en su mayor parte, viven en la propiedad lechera, así como los productores en las cuencas del sureste y sur. La mayoría de los empleados poseía bajo nivel de escolaridad, viven en la granja y son del género masculino. Dentro de los indicadores de rendimiento zootécnico, la productividad por área y por empleado, la producción de leche por vaca por día y la lactancia fueron más altas en la cuenca sur.

Palabras clave: Cuencas lecheras, perfil social, producción de leche

\section{Introdução}

O setor leiteiro tem um importante papel na ordem econômica e social do agronegócio brasileiro, com participação significativa no PIB pecuário. Esta relevância é explicada pelo volume de oferta, geração de divisas e pela importância do leite e derivados lácteos na composição da dieta alimentar humana (Ferraz, 2013). A produção de leite brasileira cresceu em média 4,2\% ao ano entre 2002 e 2012 (IBGE, 2013). Nos próximos dez anos deverá crescer a uma taxa anual entre 2,4\% e 3,3\% e passar de 37,2 bilhões de litros em 2015 para 47,5 bilhões de litros em 2025, podendo chegar a 52,7 bilhões de litros, caso atinja o máximo projetado (IBGE, 2013).

No Brasil, a cadeia produtiva do leite é distribuída por todo o país e tem expressiva heterogeneidade durante o processo de produção, tipicamente com produtores mais especializados se concentrando em bacias leiteiras tradicionais nos estados de Minas Gerais, Goiás, São Paulo e Paraná, mas com significativo crescimento da produção nas demais regiões (IBGE, 2013).

A atividade leiteira possui grande importância para o desenvolvimento socioeconômico de diversas regiões brasileiras, pois além de fixar o homem no campo, impedindo em muitos casos uma intensificação do êxodo rural, amortiza as pressões sociais nas áreas urbanas e colabora para minimização do desemprego e exclusão social.

A produção de leite necessita de soluções para problemas que vão desde a falta de qualificação profissional a dificuldades gerencial, econômica e tecnológica. Daí a importância da busca de conhecimentos, identificação e compreensão das principais características que envolvem a cadeia produtiva de leite no Brasil, analisando as informações coletadas junto aos produtores, para traçar um diagnóstico do seu perfil.

Além disso, traçar o perfil dos produtores de leite permitirá que os técnicos encontrem soluções para problemas dentro das propriedades, permitindo aumentar a qualidade e quantidade do leite produzido.

O objetivo deste trabalho foi avaliar se os diferentes perfis das principais bacias leiteiras brasileiras podem exercer influência nos desempenhos zootécnico e econômico das propriedades rurais ali localizadas. Especificamente, buscou-se avaliar a influência das bacias leiteiras sobre características sociais e culturais dos produtores de leite e de seus funcionários e as consequências que essas possíveis diferenças poderiam ter sobre os resultados de produção e produtividade do rebanho, bem como sobre a sustentabilidade do negócio leiteiro. 


\section{Material e métodos}

\section{Coleta de dados}

Foi compilado e analisado um banco de dados relativos à produtores de leite, fornecedores de uma indústria de transformação de leite e produção de lácteos de âmbito nacional de propriedades localizadas nas regiões Nordeste, Sul e Sudeste do Brasil. As informações do banco de dados compreenderam um período de 48 meses (julho/2010 a junho/2014).

Buscando diagnosticar o perfil dos produtores e as características socioculturais dos recursos humanos, questionários foram preenchidos por cada técnico ou produtor, entre julho/2015 e setembro/2015, perfazendo um total de 85 amostras de produtores de leite de diferentes regiões do território nacional. Uma amostra de 33 produtores foi gerada após a eliminação de inconsistências (falta de identificação no questionário, falta de código para acesso e informações no banco de dados e descontinuidade de preenchimento) e incongruências (dados de desempenho incompatíveis, propriedades com nomes ou códigos semelhantes, mas com dados distintos e resultados financeiros excessivamente fora da realidade).

\section{Análise estatística}

Os dados coletados foram compilados e analisados, utilizando-se o procedimento ANOVA do programa SAEG, versão 9.1 (SAEG, 2007), sendo as médias comparadas pelo teste Tukey, ao nível máximo de 5\% de erro. O modelo matemático para fundamentar a análise estatística foi:

$$
Y_{i}=\mu+A_{i}+\varepsilon_{i}
$$

em que $\boldsymbol{Y}_{i}$ é o dado referente à i-ésima bacia leiteira; $\boldsymbol{\mu}$ é a média geral observada; $\boldsymbol{A}_{i}$ é o efeito associado à i-ésima perfil do produtor e $\boldsymbol{\varepsilon}_{i}$ é o erro aleatório, associado às variações nos dados da i-ésima bacia leiteira.

\section{Resultados e discussão}

\section{Perfil social dos proprietários}

O nível de escolaridade dos produtores de leite foi influenciado pela bacia leiteira (Tabela 1). Produtores da bacia nordestina apresentaram nível de escolaridade mais elevado $(P<0,05)$ que os produtores das demais bacias. Foi um resultado que surpreendeu, dado que o nível de escolaridade naquela região é, em média, inferior ao observado nas regiões Sul e Sudeste (IBGE, 2013).

Tabela 1. Nível de escolaridade do produtor (EP), residência do produtor (RP), tempo na atividade leiteira (TA), geração familiar que a propriedade pertence (GF), expectativa de continuidade sucessória da atividade (CS).

\begin{tabular}{lccccc}
\hline \multirow{2}{*}{ Bacia } & \multicolumn{5}{c}{ Variáveis dependentes } \\
\cline { 2 - 5 } & $\mathrm{EP}^{1}$ & $\mathrm{RP}^{2}$ & $\mathrm{TA}^{3}$ & $\mathrm{GF}^{4}$ & $\mathrm{CS}^{5}$ \\
\hline Nordeste & $4,02 \mathrm{a}$ & $1,53 \mathrm{a}$ & $3,28 \mathrm{a}$ & $1,26 \mathrm{c}$ & $1,00 \mathrm{~b}$ \\
Sudeste & $3,01 \mathrm{~b}$ & $1,37 \mathrm{~b}$ & $3,07 \mathrm{a}$ & $1,64 \mathrm{~b}$ & $1,60 \mathrm{a}$ \\
Sul & $2,97 \mathrm{~b}$ & $1,04 \mathrm{c}$ & $2,80 \mathrm{~b}$ & $2,14 \mathrm{a}$ & $1,10 \mathrm{~b}$ \\
\hline
\end{tabular}

$1 / 1$ e 2 = fundamental, 3 e 4 = médio, 5 e 6 = superior, níveis completo e incompleto, respectivamente

$2 / 1=$ mora na propriedade e $2=$ mora fora da propriedade

$3 / 1=$ até 5 anos; $2=5-15$ anos; $3=15$ a 25 anos e $4=$ acima de 25 anos

$4 / 1=1^{\text {a }}$ geração; $2=2^{\mathrm{a}}$ geração; $3=3^{\mathrm{a}}$ geração; $4=4^{\mathrm{a}}$ ou mais gerações

$5 / 1=\operatorname{sim} ; 2$ = não

6/ Médias seguidas de diferentes letras minúsculas nas colunas diferem entre si $(\mathrm{P}<0,05)$

Os valores observados para o nível de escolaridade contrastaram com os resultados do estudo realizado por Barros \& Melo (2015), ao encontrarem que 54,6\% dos 141 produtores de leite estudados possuíam o $1^{\circ}$ Grau de escolaridade. Não houve diferença, entretanto, entre os produtores das bacias Sul e Sudeste $(P>0,05)$. Produtores da bacia Sul apresentaram escolaridade média, o que de certa forma, segundo Rocha Júnior et al. (2014), poderia inviabilizar o crescimento da propriedade, pois dificultaria a instalação de sistemas produtivos mais tecnológicos nas propriedades e a implantação de sistemas de gestão e de controle. 
Barros \& Melo (2015), em um estudo com o intuito de identificar as principais características socioeconômicas dos produtores de leite do Nordeste, chegaram à conclusão de que 25,5\% tinham ensino médio. Borsanelli et al. (2014) quando avaliaram fatores socioeconômicos de 171 produtores de leite (escolaridade, volume de produção diária e tempo na atividade) de 96 municípios de São Paulo, observaram que a maioria dos produtores $(40,4 \%)$ possuíam escolaridade fundamental.

Notou-se influência da bacia leiteira no hábito de residência dos produtores de leite $(P<0,05)$. Cerca de $57 \%$ dos produtores do Nordeste moravam na propriedade, situação parecida com as demais bacias, onde os produtores predominantemente residiam na propriedade, àqueles da bacia Sul, na quase totalidade $(92 \%)$ moravam na fazenda; no Sudeste, a parcela daqueles produtores que residiam na fazenda foi de $58 \%$.

De acordo com Rocha Júnior et al. (2014), a grande maioria dos entrevistados $(92,7 \%)$ no Sul residiam na própria empresa rural, o que facilita a administração e o controle da propriedade. O tempo na atividade leiteira foi influenciado pela bacia leiteira $(P<0,05)$.

Notou-se que os produtores das bacias Nordeste e Sudeste estão há mais tempo na atividade que os da bacia Sul (Tabela 1); entre os produtores das duas primeiras bacias não se detectou diferença no tempo em atividade no negócio leite $(P>0,05)$. Em média, os produtores dessas regiões estão trabalhando entre 15 e 25 anos na atividade leiteira.

Ao analisar-se o tempo na atividade leiteira, se leva em conta a capacidade de adaptações às mudanças recentes no sistema agroindustrial, bem como a inserção do produtor na atividade leiteira dentro do atual contexto competitivo. $\mathrm{O}$ alto índice de permanência do produtor na atividade leiteira deve-se ao elevado capital investido, de baixa liquidez, que mantém o produtor no setor (Rocha Júnior et al., 2014).

No que se refere ao número de gerações ao qual a propriedade está na família, observou-se que cerca de $36 \%$ dos produtores da bacia Sul pertencem à $2^{a}$ geração da família na atividade leiteira $(P<0,05)$; resultado ligeiramente superior aos produtores do Sudeste $(25 \%)$ e aos da bacia nordestina, cuja atividade no leite é formada, predominantemente, de produtores pertencentes à $1^{\text {a }}$ geração $(71 \%)$.

Observaram-se resultados significativos $(P<0,05)$ ao se avaliar o efeito das bacias sobre a expectativa de continuidade sucessória na atividade. Produtores da bacia Sudeste expressaram expectativas superiores em deixar a atividade $(P<0,05)$ que os produtores de leite das demais bacias. Em termos relativos, $42 \%$ dos produtores dessa bacia tinham expectativa de que não haja continuidade sucessória na atividade.

Não houve diferença significativa entre os produtores do Nordeste e do Sul $(P>0,05)$ quanto a expectativa de continuar na atividade (100\% e $86 \%$, respectivamente).

Segundo Costa (2010), a sucessão na agricultura familiar envolve, não apenas a transferência de um patrimônio e de capital imobilizado ao longo das sucessivas gerações, mas revela, também, a existência de verdadeiro código cultural, que orienta as escolhas e os procedimentos, dirigidos a garantir que, pelo menos, um dos herdeiros possa perpetuar o patrimônio familiar.

\section{Perfil social dos funcionários da propriedade}

Observaram-se diferenças significativas entre as bacias leiteiras quanto ao número total de funcionários da propriedade (Tabela 2). Propriedades da bacia Nordeste tiveram maior número de funcionários $(P<0,05)$ que as demais bacias; observando-se que as propriedades da região Sudeste operam com mais funcionários que aquelas do Sul. Há uma grande preocupação das empresas, de uma maneira geral, com a questão da mão de obra, tanto em termos qualitativos quanto quantitativos. Isso decorre do fato de que ela tem significativo impacto, não somente sobre a eficiência na execução das atividades necessárias ao processo, mas, principalmente, sobre os custos totais de produção (Tonet, 2015). Cabe ainda ressaltar que, além da mão de obra ser, normalmente, o segundo elemento de despesa direta na fazenda, há ainda um dispêndio elevado com encargos sociais que, na área do comércio, chega a $97 \%$ (Tonet, 2015). 
A região onde fica a bacia influenciou o número de funcionários que possuíam nível fundamental de escolaridade $(P<0,05)$. O Nordeste teve maior número de funcionários com nível de escolaridade fundamental incompleto ou completo. O baixo nível de escolaridade pode refletir no conhecimento sobre a atividade leiteira e dificultar um melhor aproveitamento e qualificação em programas de treinamento e transferência de tecnologia (Sousa et al., 2011). Segundo Costa et al. (2012), em estudo que teve por objetivo fazer um diagnóstico do perfil dos pequenos pecuaristas de leite na região nordeste, chegou-se à conclusão que, na maioria das propriedades estudadas, o número de produtores e funcionários com ensino fundamental era maior do que aqueles com nível de escolaridade mais elevados. Ainda, segundo aqueles autores, no meio rural, o nível de escolaridade é baixo pela dificuldade em conciliar os estudos com o trabalho na propriedade.

Tabela 2. Número de funcionários total (NTF), de nível fundamental (FNF), de nível médio (FNM), de nível superior (FNS), de sexo masculino $\left(\mathrm{N}^{\circ} \mathrm{M}\right)$, de sexo feminino $\left(\mathrm{N}^{\circ} \mathrm{F}\right)$, que residem na propriedade (NFR) e que residem fora da propriedade (NFF) em cada bacia.

\begin{tabular}{|c|c|c|c|c|c|c|c|c|}
\hline \multirow{2}{*}{ Bacia } & \multicolumn{8}{|c|}{ Variáveis dependentes } \\
\hline & NTF & FNF & FNM & FNS & $\mathrm{N}^{\circ} \mathrm{M}$ & $\mathrm{N}^{\circ} \mathrm{F}$ & NFR & NFF \\
\hline Nordeste & $3,64 a$ & $2,02 \mathrm{a}$ & $1,62 \mathrm{a}$ & $0,00 \mathrm{~b}$ & $3,64 \mathrm{a}$ & $0,00 \mathrm{c}$ & $3,17 \mathrm{a}$ & $0,47 \mathrm{ab}$ \\
\hline Sudeste & $3,09 b$ & $2,17 \mathrm{a}$ & $0,82 b$ & $0,10 \mathrm{a}$ & $2,26 b$ & $0,83 a$ & $2,44 b$ & $0,65 a$ \\
\hline Sul & $1,07 \mathrm{c}$ & $0,83 b$ & $0,34 \mathrm{c}$ & $0,07 \mathrm{a}$ & $0,66 \mathrm{c}$ & $0,41 b$ & $0,73 \mathrm{c}$ & $0,34 b$ \\
\hline
\end{tabular}

${ }^{1} /$ Médias seguidas de letras minúsculas distintas na coluna diferem entre si $(\mathrm{P}<0,05)$.

Verificou-se que no Sudeste o número total de funcionários com ensino fundamental incompleto ou completo é parecido com o da região Nordeste $(P>0,05)$. Já no Sul, o número de funcionários com ensino fundamental é o menor entre as bacias, mas ao se confrontar todos os níveis de escolaridade dessa bacia, notou-se a prevalência do nível fundamental entre todos os funcionários.

O número de funcionários com nível médio incompleto ou completo de escolaridade foi influenciado pela bacia $(P<0,05)$. No Nordeste existem mais funcionários com ensino médio do que nas demais bacias. Esse resultado parece contrariar a idéia generalizada de que o analfabetismo ou o baixo de nível de escolaridade é a condição mais comum na região Nordeste, assertiva reforçada por diversas literaturas (Rocha Júnior et al., 2014). Convertendo-se os índices de escolaridade para porcentagens, observa-se que nas propriedades nordestinas, $51,7 \%$ dos funcionários apresentaram nível médio, enquanto aqueles das bacias Sul e Sudeste apresentam, respectivamente, $21,4 \%$ e 26,0\%.

Houve influência da bacia leiteira no nível superior de escolaridade. As bacias Sudeste e Sul se assemelharam $(P>0,05)$ quanto ao número de funcionários com esse grau de formação $(4,34 \%$ e $7,14 \%$, respectivamente), mas ambas tiveram maior número de funcionários com ensino superior completo ou incompleto $(P<0,05)$ que as propriedades da bacia nordestina, onde, na verdade, não se observou qualquer funcionário com nível de escolaridade superior trabalhando nas propriedades dessa última região.

O gênero também é influenciado pela bacia leiteira. A bacia nordestina foi a que teve o maior número de funcionários homens $(P<0,05)$, seguida pelas propriedades localizadas no Sudeste e posteriormente às do Sul. Bazotti et al. (2012), num estudo da caracterização socioeconômica e técnica da atividade leiteira do Paraná, encontraram um valor de $93 \%$ dos responsáveis pelas propriedades leiteiras do Estado pertencentes ao sexo masculino.

No Sudeste observou-se que houve mais funcionárias do que nas demais bacias estudadas $(P<0,05)$. No Sul, $42,8 \%$ dos funcionários são do sexo feminino. Na bacia nordestina, não foram observadas representantes femininas na propriedade leiteira, possivelmente devido à existência de aspectos culturais e socioeconômicos que podem refletir nesses dados. Geralmente, a sociedade encarrega à mulher as funções domésticas onde essa se divide nos afazeres do lar, na responsabilidade materna, na formação dos filhos e trabalhos secundários para o sustento e complementação de renda familiar (Alves \& Pinho, 2011).

Houve efeito significativo $(P<0,05)$ da bacia sobre o número de funcionários que residem na propriedade. No Nordeste existe maior número de funcionários que moram na propriedade leiteira (79,3\%), seguido pelo Sudeste, com 76\% dos funcionários morando onde trabalham e no Sul, 71,4\% do total de funcionários moram na propriedade. Levando em consideração todas as bacias estudadas, $76,4 \%$ 
dos funcionários residem na propriedade leiteira e 23,6\% dos funcionários não moram na propriedade em que trabalham.

Os resultados provavelmente refletiram as dificuldades enfrentadas pelo país, no que concerne à moradia, em especial na região nordestina. Segundo Leite (2014), além dos problemas que atingem as cidades, as desigualdades regionais reforçam a exclusão do acesso à cidade e à moradia adequada para parcelas ainda maiores da população.

\section{Indicadores de desempenho zootécnico}

Um dado interessante verificado nas diferentes bacias foi que o tamanho das propriedades variou entre elas (Tabela 3). Propriedades na bacia nordestina são, em média, maiores $(P<0,05)$ que as fazendas das demais bacias. No Sudeste, as propriedades são de tamanho intermediário entre as do Nordeste e as do Sul, significativamente menores dentre as bacias estudadas. Essas diferenças de áreas são relativamente compreensíveis e as justificativas remontam à época do Brasil império, resvalando pelo início da primeira república e num continuátio, embora em menor grau, até os dias atuais.

No passado, possuir terra era sinônimo de poder e as figuras proeminentes do país, em especial políticos de renome, oficiais das forças armadas de alta patente ("coronéis") e assemelhados, tratavam de constituir e ratificar esse poder amealhando hectares em suas respectivas áreas de influência. É preciso ressaltar que naquele período, a maior parte da população vivia no meio rural, a serviço dos proprietários como meeiros, o que conferiu aos primeiros, o poder de influenciar na vontade política e na subsistência desses últimos (Dias, 2006) e, por conseguinte, nos destinos políticos da região de sua influência. Também foi significativo o fato de que, com maiores desafios impostos por condições climáticas predominantes na bacia Nordeste, a manutenção da escala de produção depende, em grande parte, da extensão da terra, para garantir maior número de animais de baixa performance, numa terra de menor capacidade de suporte. Ilustrou essa última assertiva, os dados encontrados neste trabalho, onde se verificou que no Nordeste, foram suportadas, em média, 0,29 vacas/ha, contra 0,39 e 2,03 vacas/ha, respectivamente, nas propriedades localizadas nas bacias do Sudeste e do Sul.

Tabela 3. Área (A), Produtividade por Área (PA), Produtividade por funcionário (PF), Vacas em lactação (VL), Produção de leite (PL), Produção por vaca em lactação (PV).

\begin{tabular}{lccccc}
\hline \multirow{2}{*}{ Bacia } & \multicolumn{5}{c}{ Variáveis dependentes } \\
\cline { 2 - 6 } & $\mathrm{A}^{1}$ & $\mathrm{PA}^{2}$ & $\mathrm{PF}^{3}$ & $\mathrm{VL}^{4}$ & $\mathrm{PL}^{5}$ \\
\hline Nordeste & $287,4 \mathrm{a}$ & $142,4 \mathrm{c}$ & $171,1 \mathrm{c}$ & $57,8 \mathrm{~b}$ & $701,9 \mathrm{a}$ \\
Sudeste & $78,2 \mathrm{~b}$ & $410,2 \mathrm{~b}$ & $246,2 \mathrm{~b}$ & $68,7 \mathrm{ab}$ & $8,3 \mathrm{c}$ \\
Sul & $14,1 \mathrm{c}$ & $1648,3 \mathrm{a}$ & $347,8 \mathrm{a}$ & $88,0 \mathrm{a}$ & $53,9 \mathrm{c}$ \\
\hline
\end{tabular}

1/ Valores em ha; ${ }^{2 /}$ Valores em L/ha/ano; ${ }^{3 /}$ Valores em R $\$ / \mathrm{L} ;{ }^{4}$ / Valores em \% sobre o total de vacas;

$5 /$ Valores em L/dia;

6/ Médias na coluna seguidas de letras distintas diferem entre si ao nível de 5\%

Com uma menor produtividade diária de leite, um menor porcentual de vacas em lactação e uma maior área disponível para a exploração do negócio leiteiro, não surpreende o fato das propriedades leiteiras da bacia Nordeste terem apresentado a menor produtividade por área $(P<0,05)$. Ainda que a produção de leite tenha sido maior nas fazendas dessa região, aparentemente isso não foi suficiente para superar as produtividades por área alcançadas pelas propriedades das demais bacias. Notou-se claramente que a eficiência aumentou na região Sudeste, mas, ainda assim, foi superada pela produtividade alcançada por produtores da bacia Sul.

A produtividade por área foi um importante indicador de eficiência técnica e econômica da atividade leiteira e, até certo ponto, contribuiu para um benchmark com outras atividades agropecuárias, pois, relacionado com o valor pago pelo litro de leite, determinou a rentabilidade de cada hectare ocupado pela atividade e o quanto ela pode ser competitiva (Moreira, 1993).

No presente trabalho, nenhuma das bacias alcançou, na média, valores considerados bons ou muito bons, conforme preconizado por Yamaguchi et al. (2003), que também constataram baixa eficiência técnica nas propriedades Nordeste e Sudeste. 
Foram observados resultados significativos ao se avaliar o efeito das bacias sobre a produtividade por funcionário. Conforme o esperado, nas propriedades da bacia Sul a produtividade por funcionário superou aquelas observadas nas outras bacias estudadas $(P<0,05)$, uma vez que, o número de funcionários foi comparativamente menor. Possivelmente uma maior especialização da mão de obra nas regiões Sul e Sudeste, subsidiou em parte os resultados aqui observados, mas foi possível ainda supor que o fato dos produtores do Sul, em maior número, morarem na propriedade também contribuiu para esse fenômeno. No Sudeste, os resultados foram medianos em relação a produtividade dos funcionários, ficando entre os valores observados no Sul e no Nordeste.

As bacias leiteiras tiveram efeitos significativos sobre a porcentagem de vacas em lactação $(P<$ $0,05)$. Propriedades da bacia do Sul apresentaram resultados superiores $(P<0,05)$ que as propriedades das demais bacias estudadas. De acordo com Faria (2007), o ideal seria em torno de 80 a $85 \%$ de vacas lactantes em relação ao total de vacas do rebanho, número só alcançado pelas propriedades da bacia Sul. Não houve diferença entre as propriedades das bacias Nordeste e Sudeste $(P>0,05)$, mas ambas apresentaram resultados expressivamente abaixo do desejável sugerido por aquele autor.

Em termos absolutos, o número total em cada bacia foi de 83,8; 30,8 e 28,7 vacas no rebanho, respectivamente para Nordeste, Sudeste e Sul. Esse número está atrelado, muito provavelmente, à capacidade de suporte de vacas das propriedades estudadas em cada bacia. Como na média, as propriedades do Sul alojaram mais vacas que as do Sudeste e essas, por seu turno, alojaram mais vacas que as do Nordeste, o resultado era, de certa forma, esperado.

Neves et al. (2011) em estudo da caracterização dos produtores e dos sistemas de produção de leite de Petrolina/PE, encontraram menor relação de vacas em lactação $(52,1 \%)$, provocados pelo intervalo de partos (IP) maior. Segundo Ferreira \& Teixeira (2000), o longo intervalo de partos acarreta prejuízos aos produtores por diminuir o número de vacas em lactação no rebanho, os animais para venda ou reposição e a produção de leite total da propriedade.

A produção diária de leite, em litros por dia, foi maior nas fazendas da bacia nordestina, seguidas da produção das fazendas do Sul e Sudeste $(P<0,05)$. Essa maior produção talvez seja fruto da necessidade de maior escala para compensar a menor produtividade por funcionário e por vaca. Além disso, como já observado anteriormente, ainda que a produção diária por vaca seja menor no Nordeste $(P<0,05)$, 0 rebanho foi significativamente maior nessas fazendas. As propriedades do Sudeste produziram mais leite que as do Nordeste, mas aquelas são sobejamente superadas pelas do Sul. Esses resultados se assemelharam aos achados de Bazotti et al. (2012) que, num estudo do diagnóstico do setor leiteiro paranaense abordando caracterização socioeconômica e técnica da atividade, também observaram elevada produção por vaca, tendo os produtores atingidos valores de 19,2 litros/vaca/dia. Numa região do Nordeste, Costa et al. (2012), em uma unidade de produção de leite bovino a pasto, observaram produções média diárias de 7,87 e 10,3 kg/animal/dia, nos dois anos do estudo.

\section{Conclusões}

Existem diferenças no perfil social dos produtores e dos funcionários, assim como no desempenho produtivo das propriedades no Brasil em função da bacia leiteira. No Nordeste foram observados níveis de escolaridade mais elevado entre os produtores, que em sua maioria (57\%), residem na propriedade leiteira. Quanto ao tempo na atividade leiteira, os produtores dessa região estão, em média, entre 15 e 25 anos.

Percebe-se na bacia nordestina que o número total de funcionários das propriedades foi maior que as demais regiões. No Sul esse resultado é menor, pois há uma expectativa de contribuição de mão de obra familiar. A maioria dos funcionários das propriedades estudadas possui baixo nível de escolaridade (fundamental incompleto ou completo), 76,4\% residem na propriedade onde trabalham e $80,9 \%$ são do gênero masculino.

Quanto aos indicadores de desempenho zootécnico, a produtividade por área e por funcionário, a produção de leite por vaca por dia e por lactação foram superiores na bacia Sul. 


\section{Referências}

Alves, H. C. R., \& Pinho, H. J. (2011). Condição do produtor na direção dos estabelecimentos agropecuários no Nordeste. Informe Rural Etene., 5.

Barros, L. S. S., \& Melo, A. D. (2015). Perfil sócio-econômico dos produtores de leite, vinculados aos laticínios registrados no serviço de inspeção estadual (SIE) da Coordenadoria Regional/ADAB de Vitória da Conquista-BA. Agropecuária Científica No Semiárido, 10(4), 20-30. https://doi.org/10.30969/acsa.v10i4.496

Bazotti, A., Nazareno, L. R., \& Sugamosto, M. (2012). Caracterização socioeconômica e técnica da atividade leiteira do Paraná. Revista Paranaense de Desenvolvimento, 123, 213-234.

Borsanelli, A. C., Samara, S. I., Ferraudo, A. S. \& Dutra, I. S. (2014). Escolaridade e volume de produção têm associação com a percepção de risco de produtores de leite no uso de produtos veterinários. Pesquisa Veterinária Brasileira, 34(10):981-989.

Costa, A. G., Sousa, M. F. A., Arré, F. A., Portela, G. L. F., \& Terto, G. G. (2012). Perfil das granjas leiteiras do Município de Caxias-MA. PUBVET, 6, Art-1472.

Costa, J. H. S., Santos, L. F. D., \& Dantas, R. T. (2012). Análise econômica de uma unidade de produção de leite bovino do brejo paraibano. Revista Verde de Agroecologia e Desenvolvimento Sustentável, $7(5), 46-54$.

Costa, M. A. S. (2010). Fatores econômicos e sociais da sucessão na agricultura familiar: um estudo sobre o oeste catarinense. Dissertaçâo de Mestrado. Universidade Federal de Viçosa, Viçosa. 159p.

Dias, J. C. (2006). 500 anos de leite no Brasil. Calandra Editorial.

Faria, V. P. (2007). Fatores que afetam a eficiência. DBO Mundo Do Leite 27:2-15.

Ferraz, J. V. (2013). Anualpec 2013: anuário da pecuária brasileira. São Paulo: FNP.

Ferreira, A. M., \& Teixeira, N. M. (2000). Estimativas de mudanças na produção de leite com a variação do intervalo de partos em rebanhos bovinos. Revista Brasileira de Reprodução Animal, 24(4), 177 181.

IBGE. (2013). Pesquisa Trimestral do Leite. http://www.sidra.ibge.gov.br/bda/tabela/listabl.asp?z=t\&o=24\&i=P\&c=1086

Leite, S. (2014). Direito à moradia: desafios para sua efetivação no Nordeste. http://dssbr.org/site/opinioes/direito-a-moradia-desafios-para-sua-efetivacao-no-nordeste/

Moreira, D. A. (1993). Medida da produtividade em atividades de serviços: alguns problemas e soluções. Revista Indicadores Da Qualidade e Produtividade, 1, 59-78.

Neves, A. L. A., Pereira, L. G. R., Santos, R. D., Araújo, G. G. L., Carneiro, A. V., Moraes, S. A., Spaniol, C. M. O., \& Santos, A. (2011). Caracterização dos produtores e dos sistemas de produção de leite no perímetro irrigado de Petrolina/PE. Revista Brasileira de Saúde e Produção Animal, 12(1).

Rocha Júnior, B. D., Pasqual, C. A., \& Finamore, E. B. (2014). O perfil dos produtores de leite, o processo de sucessão e a renda bruta no Rio Grande do Sul: análise do Corede Produção. Revista Teoria e Evidência Econômica, 20(42). https://doi.org/10.5335/rtee.v20i42.4476

SAEG. (2007). Sistema para análises estatísticas. Viçosa: UFV.

Sousa, M. R. P., Ristow, A. M., Nogueira, E. B., Torres, R. A., \& Cortez, M. A. S. (2011). Caracterização de pequenas unidades produtoras de leite na região Centro e Noroeste do estado do Rio de Janeiro. Revista Brasileira de Ciência Veterinária, 18(2-3), 79-84. https://doi.org/10.4322/rbcv.2014.124

Tonet, H. C. (2015). Liderança e gestão de pessoas em ambientes competitivos. Editora FGV.

Yamaguchi, L. C. T., Martins, P. C., \& Carneiro, A. V. (2003). Eficiência técnica e econômica da atividade leiteira: região Sul do Brasil. Congresso Brasileiro de Economia e Sociologia Rural, 41.

Histórico do artigo:

Recebido: 8 de julho, 2020

Aprovado: 6 de agosto, 2020.

Disponível online: 12 de novembro, 2020.
Licenciamento: Este artigo é publicado na modalidade Acesso Aberto sob a licença Creative Commons Atribuição 4.0 (CC-BY 4.0), a qual permite uso irrestrito, distribuição, reprodução em qualquer meio, desde que o autor e a fonte sejam devidamente creditados. 